\title{
Analysis on Dynamic Characteristics of Landscape Patterns in Hailer and around Areas
}

\author{
Hongbin Zhang ${ }^{1,2,3}$, Guixia Yang ${ }^{1,2,3}$, Qing Huang ${ }^{2,3}$, Gang $\operatorname{Li}^{1,2,3}$, \\ Baorui Chen ${ }^{1,2,3}$, and Xiaoping Xin ${ }^{1,2,3, *}$ \\ ${ }^{1}$ Hulunber Grassland Ecosystem Observation and Research Station, Beijing 100081, China \\ ${ }^{2}$ Key Laboratory of Resource Remote Sensing and Digital Agriculture, \\ Ministry of Agriculture, Beijing 100081, China \\ ${ }^{3}$ Chinese Academy of Agricultural Science Insititute of Agricultural Resource and \\ Regional Planning, No.12 Zhongguancun South St., Haidian District, Beijing 100081, China \\ Tel.:+86-10-82109622-138 \\ xinxp@sina.com, hbzhang@caas.net.cn
}

\begin{abstract}
This paper analyzed the spatial-temporal dynamic changes of landscape patterns in Hailer and around areas. Firstly, landscape patterns types of research area were divided into water, sand, farmland, city and grassland based on remote sensing images of 1986, 1991, 1996 and 2001 and field investigation. Then the grassland was classified into higher coverage grassland, high coverage grassland, medium coverage grassland and low coverage grassland by Normalized Difference Vegetation Index. Finally, the spatial-temporal dynamic changes of above-mentioned eight kinds of landscape patterns were analyzed using landscape ecology principle. The results indicated that human activities intensified significant from 1986 to 2001 in research area. The area of grassland landscape decreased quickly, and the fragmentation extent intensified. The dominant landscape in research area changed from higher-high coverage grassland to medium-low coverage grassland. The expansion of sand landscape is obvious in periphery of road, city and farmland. The grassland vegetation degenerated seriously. Fragmentation of city landscape lightened, and city landscape patches tended to decrease and centralized. Economy development pattern of research area is in a stage that is transforming from extensive pattern to intensive urbanization pattern.
\end{abstract}

Keywords: Landscape patterns, Hulunbuir, Spatial-Temporal Dynamic.

\section{Introduction}

Landscape spatial patterns are strongly connected with dynamic procession (Wu Jianguo et al., 2001; Nagendra $\mathrm{H}$ et al., 2006). Biologic factors, abiotic factors and human factors drive landscape patterns spatial-temporal evolution together and restrict development direction of ecological process. Analysis on landscape patterns spatialtemporal evolution can open out driving mechanism and development trend of

\footnotetext{
* Corresponding author.
} 
ecological process (Su Y et al., 2005; Wu R et al., 2002; Huang Qing et al., 2007; He Chunyang et al., 2001; Zhang Yili, et al., 2006). In the study of grassland degeneration, analysis on the landscape patterns spatial-temporal evolution makes for understanding relations between landscape pattern and grassland degeneration process and provides scientific foundations on grassland ecological system management and recovery(Wang Hui et al., 2006; Wamg Mulan et al., 2007; Wamg Mulan et al., 2007). So many experts and scholars devote themselves to studying landscape patterns spatial-temporal evolution in grassland deterioration process. But most of them focus on highly degraded grasslands. Their natural habitats are not good and they are very easy to be disturbed by outside environment (Li Yuechen et al., 2006; Cao Chengyou et al., 2006; Tao Weiguo et al., 2007; Chen quangong et al., 2007; Chen Quangong et al., 1998; Wang Qian et al., 2007; Li Jianpinget al., 2006; Wu Yunna et al., 2000; Liu Xuelu et al., 2000; Zhang Tao et al., 2007;). So almost nobody studies meadow steppe grassland and their ecology recovery functions are very good.

Hulunbuir grassland is one of the grasslands which are conserved most completed (Pan Xueqing et al., 1992). It has unique location features and typical ecological system features and advanced pasture animal husbandry production and management methods. At the same time, it is an important husbandry manufacturing base in northern China fescue grassland (Lo Bo et al., 1997; Lu Xinshi et al., 2002). But since the 1980 s, under pressures of economy development and accretion of population, area of farmland and towns has been increasing rapidly in Hulunbuir grassland and degeneration tendency is still very serious. Vegetation productivity has fallen significantly. Sand expands promptly. Landscape spatial pattern changes violently. Especially Halaer area and surrounding area are typical representing regions in which human actions influence most strongly (Liu Dongxie et al., 2007; Komatsu Y et al., 2005; Zhao Huiying et al., 2007; Zhang Deping et al., 2007; Ma Yuling et al., 2004; Nie Haogang et al., 2005). So association study on intra-regional landscape spatial pattern has important academic value and useful efforts in Hulunbuir grassland ecological system management and recovery (Ren Jizhou et al., 1998).

\section{Material and Method}

\subsection{Survey Region Overview}

Hulunbuir grassland is located in the west of Daxinanling and from east to west distributed regularity. It spans forest steppe, meadow steppe and steppe. It is one of potential grass yield and optimal herbaceous regions in Inner Mongolia grassland. We selected central region of Hulunbuir grassland as survey region including Hailer, Old Barag Banner, parts of Evenk Autonomous Banner and the whole area is $3160.82 \mathrm{~km} 2$. In survey region, hydrothermal condition is very good and it belongs to temperate continental climate. Hailer River and Yimin River mixes here. There are abundant water resource and 110 days frost free period. Mean annual temperature is $2^{\circ} \mathrm{C}$.The soil is mainly chernozem. The area of farmland is very large. Main land 
types include city, farmland, grassland, sand and water. It has convinent transportation and rich economies. It also is population accumulation area in Hulunbuir grassland. Especially Hailer is political, economical and cultural centre and main resources collection and distribution point of Hulunbuir. It also is the point of human action maximum intensity region in Hulunbuir grassland.

\subsection{Remote Sensing Data Analysis}

The selected Data is three terms $1 / 4$ view LandSat-5 TM data and one term 1/4 view LandSat-7 ETM data from earth station of Chinese Academy of Sciences.

Table 1. The parameters of remote sensing data

\begin{tabular}{ccccc}
\hline Number & Orbit & $\begin{array}{c}\text { Imaging } \\
\text { Time }\end{array}$ & Satellite & $\begin{array}{c}\text { Average } \\
\text { Cloud }\end{array}$ \\
\hline 1 & $123 / 25$ & 1986.8 .6 & LandSat5 & $<10 \%$ \\
2 & $123 / 25$ & 1991.8 .4 & LandSat5 & $<10 \%$ \\
3 & $123 / 25$ & 1996.7 .16 & LandSat5 & $<10 \%$ \\
4 & $123 / 25$ & 2001.7 .22 & LandSat7 & $<10 \%$ \\
\hline
\end{tabular}

Because the above data belongs to primary production, we must use Erdas Image software to adjust images and registration error is controlled in 0.5 pixel. At the same time, we transferred projection to Albers Equal Area projection (the first and second normal latitude and central meridian are: $25,47,105)$.

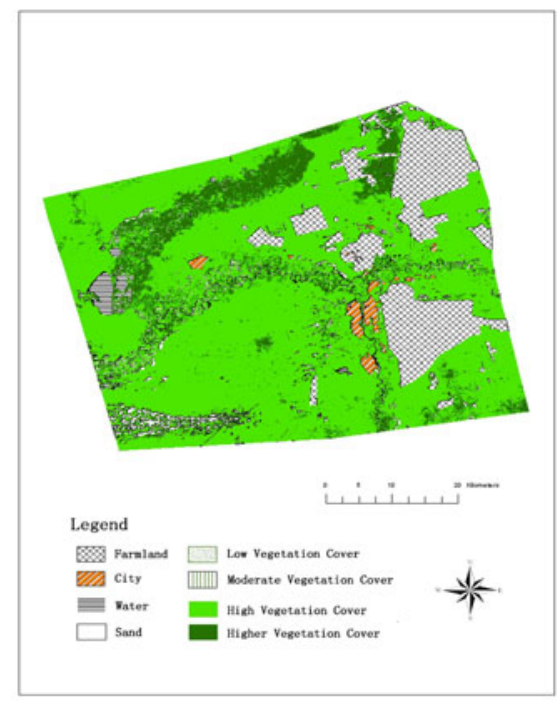

Fig. 1. The distribution map of the research area landscapes, 1986

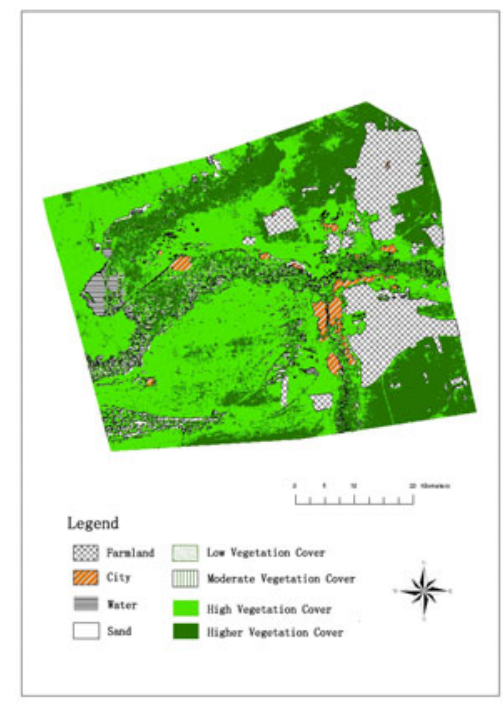

Fig. 2. The distribution map of the research area landscapes, 1991 


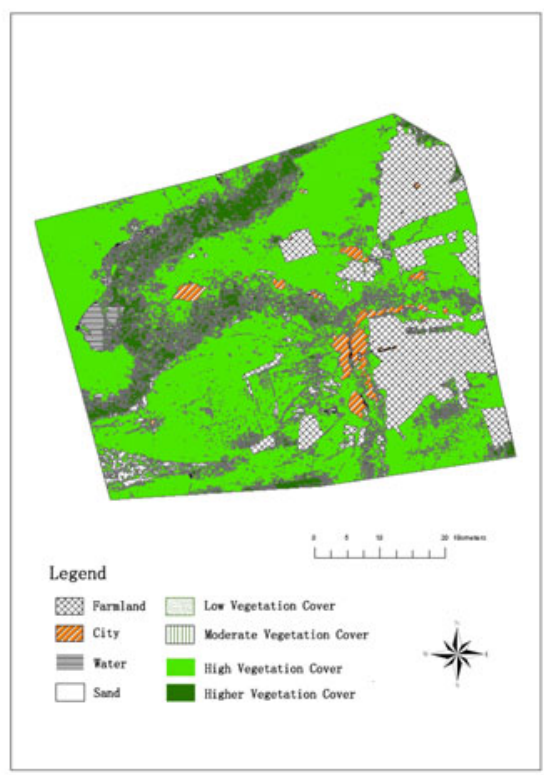

Fig. 3. The distribution map of the research area landscapes, 1996

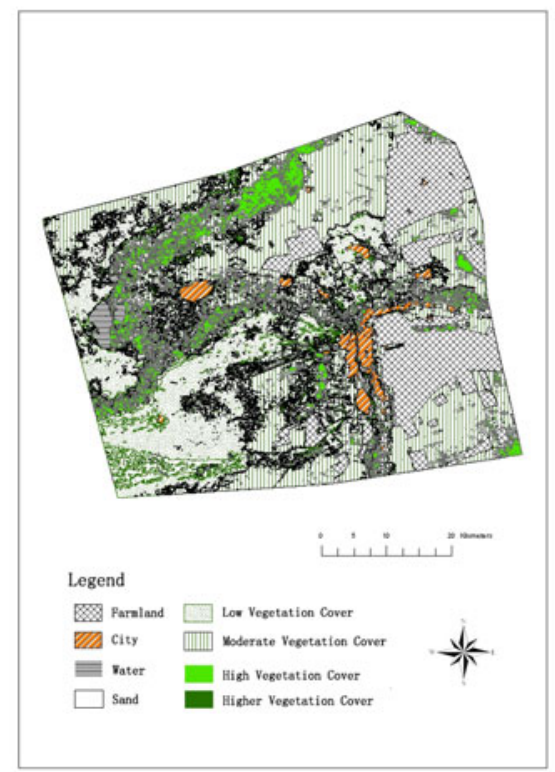

Fig. 4. The distribution map of the research area landscapes, 2001

Based on secular field study in survey region and combined with supervised classification methods, we used Erdas Image software to interpret the images and divided to water, sand, farmland, city, higher coverage grassland, high coverage grassland, medium coverage grassland and low coverage grassland. And the grassland was classified by Normalized Difference Vegetation Index (Tian Qingjiu et al., 1998).NDVI vegetation indexes of higher coverage grassland, high coverage grassland, medium coverage grassland and low coverage grassland are separately $(0,0.25), \quad(0.25,0.5)$, $(0.5,0.75), \quad(075,1)$. At last, ArcGIS was used to make 1986, 1991, 1996, 2001 landscape pattern distribution maps and the results as shown in the figure 1-4.

\subsection{Selection of Landscape Indicators}

Landscape indicators can highly condense landscape pattern information and reflect structure making up and spatial configuration features. According to features of survey region, landscape indicators selected not only patch area, patch quantity such basic parameters, but also landscape area proportion, patch density and the largest patch index.

1. Proportion of landscape area: Patches area of a type landscape accounts for the whole area, and it indicates incidence of this type patches in landscape. The formula is 
$\operatorname{PLAND}(\%)=\frac{\sum_{\mathrm{j}=1}^{\mathrm{n}} \mathrm{a}_{\mathrm{ij}}}{\mathrm{A}}(100)$

$\mathrm{a}_{\mathrm{ij}}$ : the area of $\mathrm{j}$ patch in $\mathrm{i}$ landscape; $\mathrm{A}$ : whole area.

2. Patch Density: ratio of patches quantity to area in a type landscape and it indicates different type landscape patches fragmentation degree and the whole landscape fragmentation degree. The formula is

$\mathrm{PD}=\frac{\mathrm{N}_{\mathrm{i}}}{\mathrm{A}}(1000000)$

A: whole area; $\mathrm{N}_{\mathrm{i}}$ : patches quantity in i type landscape ; unit: each/ km2

3. Large patch indicator: ratio of the largest patch area to whole landscape area and it indicates species richness and diversity. The formula is

LPI $(\%)=\frac{\max \left(\mathrm{a}_{\mathrm{i}}\right)}{\mathrm{A}}(100)$

A: whole area; $\max \left(a_{i}\right):$ the largest patch area in $i^{\text {th }}$ type landscape.

\subsection{Land Utilization Conversion Ratio Calculation}

Use land utilization conversion ratio formula $K=\frac{U_{b}-U_{a}}{U_{a} T} 100 \%$ to calculate season year dynamic fluctuation velocity between types of landscape in survey region. In above formula, $K$ is a sort of land utilization type dynamical degree in $T$ timeslot; $U_{b}$ and $U_{a}$ are separately a sort of land utilization type quantity in childhood studies and final stage. $T$ is the length of study period and the unit is year to express annual percentage change of a sort land utilization type.

\section{Results Analysis}

\subsection{Land Utilization Conversion Ratio Calculation}

According to 1986, 1991, 1996, 2001 landscape type distribution maps, Fragstats was used to extract landscape indices and the results as shown in table 2.

From landscape area changes in table 2, area of every type landscape has wider fluctuation. Compared with 1986, landscapes of city, sand, farmland, low coverage grassland and medium coverage grassland expanded quickly and the expanded areas separately are $29.46,75.77,51.8,725.42,1354.78 \mathrm{~km} 2$. At the same time, landscapes of water, high coverage grassland tended to reduce and the reduced areas separately are $24.57,1876.85,335.81 \mathrm{~km} 2$. In the mass, the whole area reduced $132.46 \mathrm{~km} 2$. 
From landscape fragmentation features, compared with 1986, in 2001 patches quantity increased $54.99 \%$, the largest patch area reduced $58.24 \%$ and patches density increased $55 \%$. The landscape fragmentation degree increased significantly. But landscape species richness and diversity decreased significantly. Especially grassland landscape fluctuated intensely and weakness species increased in grassland community. A mount of poisonous plants started to emerge. The leading landscapes changed from higher and high coverage grasslands to medium and low coverage grasslands.

Table 2. Landscape index of research area, 1986,1991,1996,2001

\begin{tabular}{|c|c|c|c|c|c|c|c|c|c|c|}
\hline Year & Landscape Index & City & Sand & Farmland & Water & $\begin{array}{l}\text { Low } \\
\text { Vegetation } \\
\text { Cover }\end{array}$ & $\begin{array}{l}\text { Moderate } \\
\text { Vegetation Cover }\end{array}$ & $\begin{array}{l}\text { High } \\
\text { Vegetation } \\
\text { Cover }\end{array}$ & $\begin{array}{l}\text { Higher } \\
\text { Vegetation } \\
\text { Cover }\end{array}$ & $\begin{array}{l}\text { Research } \\
\text { Area }\end{array}$ \\
\hline & $\mathrm{CA}\left(\mathrm{KM}^{2}\right)$ & 42.08 & 65.23 & 440.51 & 83 & 0.86 & 25.43 & 2164.2 & 342.32 & 3163.63 \\
\hline $\begin{array}{l}1 \\
9\end{array}$ & PLAND(\%) & 1.33 & 2.06 & 13.92 & 2.62 & 0.03 & 0.80 & 68.41 & 10.82 & 100 \\
\hline \multirow{3}{*}{$\begin{array}{l}8 \\
6\end{array}$} & $\mathrm{NP}($ 个) & 50 & 1187 & 42 & 2131 & 174 & 3308 & 5379 & 7136 & 19407 \\
\hline & LPI(\%) & 0.33 & 1.07 & 5.02 & 0.60 & 0 & 0.05 & 32.72 & 4.89 & 32.72 \\
\hline & $\mathrm{PD}\left(\right.$ 个 $\left./ \mathrm{KM}^{2}\right)$ & 0.02 & 0.38 & 0.0133 & 0.68 & 0.06 & 1.05 & 1.70 & 2.26 & 6.16 \\
\hline 1 & $\mathrm{CA}\left(\mathrm{KM}^{2}\right)$ & 65.11 & 86.24 & 398.98 & 120.54 & 0.6 & 10.35 & 1546.05 & 935.76 & 3163.63 \\
\hline 9 & PLAND(\%) & 2.06 & 2.73 & 12.61 & 3.81 & 0.02 & 0.33 & 48.87 & 29.58 & 100 \\
\hline 9 & $\mathrm{NP}($ ( ) & 38 & 2130 & 42 & 2940 & 91 & 11597 & 9922 & 1324 & 28084 \\
\hline \multirow[t]{2}{*}{1} & LPI(\%) & 0.77 & 0.32 & 5.22 & 2.21 & 0 & 0.01 & 20.92 & 5.23 & 20.92 \\
\hline & $\mathrm{PD}\left(\right.$ 个/KM $\left.{ }^{2}\right)$ & 0.01 & 0.67 & 0.01 & 0.93 & 0.03 & 3.67 & 3.14 & 0.42 & 8.88 \\
\hline 1 & $\mathrm{CA}\left(\mathrm{KM}^{2}\right)$ & 70.79 & 86.33 & 483.81 & 66.83 & 0.59 & 18.60 & 2081.86 & 354.82 & 3163.63 \\
\hline 9 & PLAND(\%) & 2.24 & 2.73 & 15.29 & 2.11 & 0.02 & 0.59 & 65.81 & 11.22 & 100 \\
\hline 9 & $\mathrm{NP}($ 个) & 29 & 3587 & 36 & 1210 & 69 & 3098 & 4700 & 6363 & 19092 \\
\hline \multirow[t]{2}{*}{6} & LPI $(\%)$ & 1.10 & 0.52 & 6.48 & 0.59 & 0 & 0.04 & 31.52 & 4.83 & 31.52 \\
\hline & $\mathrm{PD}\left(\right.$ 个 $\left./ \mathrm{KM}^{2}\right)$ & 0.01 & 1.13 & 0.01 & 0.38 & 0.02 & 0.98 & 1.49 & 2.01 & 6.03 \\
\hline 2 & $\mathrm{CA}\left(\mathrm{KM}^{2}\right)$ & 71.54 & 141 & 492.31 & 58.43 & 726.28 & 1380.21 & 287.35 & 6.51 & 3163.63 \\
\hline 0 & PLAND(\%) & 2.26 & 4.46 & 15.56 & 1.85 & 22.96 & 43.63 & 9.08 & 0.21 & 100 \\
\hline 0 & $\mathrm{NP}($ (个) & 34 & 5847 & 57 & 1367 & 9114 & 9054 & 4078 & 527 & 30078 \\
\hline \multirow[t]{2}{*}{1} & LPI $(\%)$ & 1.22 & 1.03 & 6.28 & 0.57 & 11.48 & 13.66 & 4.26 & 0.03 & 13.66 \\
\hline & $\mathrm{PD}\left(\right.$ 个 $\left./ \mathrm{KM}^{2}\right)$ & 0.01 & 1.85 & 0.02 & 0.43 & 2.88 & 2.86 & 1.29 & 0.17 & 9.51 \\
\hline
\end{tabular}

Note: CA (Class Area):The sum of the areas of all patches of the corresponding patch type. NP(Number of Patches):The number of patches of the corresponding patch type.

\subsection{Landscape Type Area Percent Conversion}

According to landscape type areas in different period in survey region in table 2, took advantage of land utilization percent conversion formula to calculate annual land utilization percent conversion (table 3).

From annual land utilization percent conversion in table 3, from 1986 to 2001, in the fifteen years areas of city, sand, farmland, low coverage grassland and medium coverage grassland expanded quickly, especially low and medium coverage grasslands. On the other hand, areas of water, higher and high coverage grasslands reduced significantly. On the whole, the grassland degeneration trend was very obvious. Especially from 1996 to 2001, medium and low coverage grasslands expanded dramatically and annual expanded areas account to 14 to 245 times. On the other hand, areas of high and higher coverage grasslands deduced obviously but sand expanded quickly. Grassland vegetation condition deteriorated sharply. 
Table 3. The rate of dynamic changes of landscape types area in survey region. Unit: $\%$.

\begin{tabular}{lllll}
\hline Type of Land & $K_{1986-1991}$ & $K_{1991-1996}$ & $K_{1996-2001}$ & $K_{1986-2001}$ \\
\hline City & 10.95 & 1.74 & 0.21 & 4.67 \\
$\quad$ Sand & 6.44 & 0.02 & 12.67 & 7.74 \\
$\quad$ Farmland & -1.89 & 4.25 & 0.35 & 0.78 \\
$\quad$ Water & 9.05 & -8.91 & -2.51 & -1.97 \\
$\quad$ Low Vegetation & -6.05 & -0.33 & 24599.66 & 5623.41 \\
$\begin{array}{l}\text { Cover } \\
\quad \text { Moderate }\end{array}$ & -11.86 & 15.94 & 1464.10 & 355.17 \\
$\begin{array}{l}\text { Vegetation Cover } \\
\quad \text { High Vegetation }\end{array}$ & -5.71 & 6.93 & -17.24 & -5.78 \\
$\begin{array}{l}\text { Cover } \\
\text { Higher Vegetation }\end{array}$ & 34.67 & -12.42 & -19.63 & -6.54 \\
Cover & & & \\
\hline
\end{tabular}

\subsection{Landscape Type Spatial Transformation}

According to 1986 and 2001 landscape type distribution maps in survey region, ArcGIS software was used to extract land utilization transformation matrix (table 4).

Table 4. Transformation matrix of landscape types in research area, 1986-2001 Unit: $\mathrm{km}^{2}$

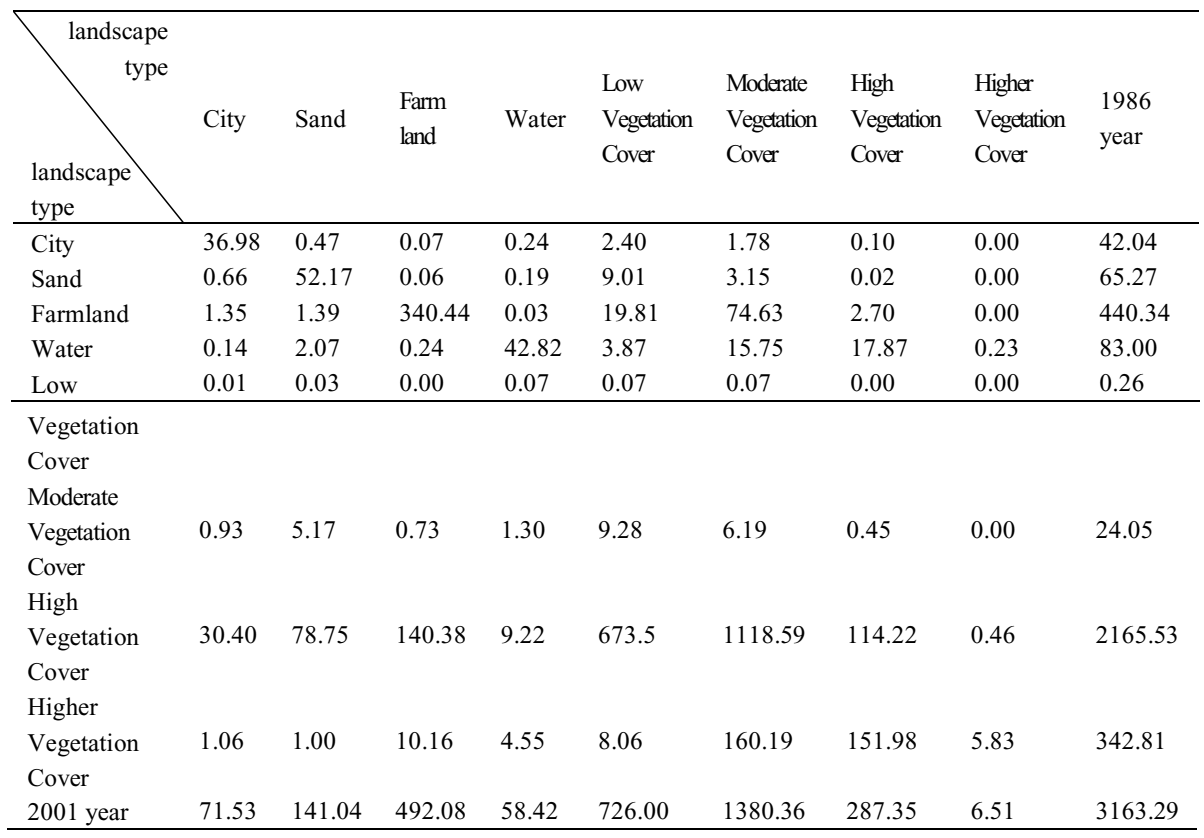


From landscape type spatial transformation situation in table 4, from 1986 to 2001, in the fifteen years, landscape spatial transformation was obviously and tended to reduce. There were $32.4 \mathrm{~km} 2$ grassland landscape transformed to city accounting for $45.3 \%$ of 2001 's city landscape, $84.95 \mathrm{~km} 2$ grassland landscape transformed to sand accounting for $60.23 \%$ of 2001 's sand landscape, $151.27 \mathrm{~km} 2$ grassland landscape transformed to farmland accounting for $30.74 \%$ of 2001 's farmland landscape. Besides there are $45.45 \%$ water landscape transformed to different coverage grasslands and $2.49 \%$ transformed to sand landscape.

Every grassland landscape type transformed dramatically. There was $673.5 \mathrm{~km} 2$ higher coverage grassland changed to low coverage grassland accounting for $92.77 \%$ of 2001's low coverage grassland. And there were $1118.59 \mathrm{~km} 2$ higher coverage grassland and $160.19 \mathrm{~km} 2$ high coverage grassland transformed to medium coverage grassland separately accounting for $81.04 \%$ and $11.60 \%$ of 2001 's medium coverage grassland. There was $151.98 \mathrm{~km} 2$ high coverage grassland transformed to higher coverage grassland accounting for 52.89\% of 2001's higher coverage grassland. On the whole, grassland vegetation degenerated seriously.

\subsection{Single Landscape Type Analysis}

The city landscape area was expanding in the fifteen years and expanded $4.67 \%$ every year. The occupied area was mainly grassland and farmland. Especially after Hulunbuir city began to take out reform of economic system from 1988, city construction made great development to make city area expand quickly. From 1986 to 1991 annual city area expanded $10.95 \%$. Besides, city landscape patches quantity and density tended to decline, but the largest patch index tended to increase obviously. Overall city landscape fragment degree declined. This condition matched very well with the actual situation that degree of urbanization had enhanced in the past 15 years in survey region.

In the past 15 years, annual farmland landscape increased $0.78 \%$ and occupied area mainly was different coverage grasslands landscape. Because strict returning cultivated land measures were taken out after broad scale land clearing from 1980 to 1986 to make farmland landscape area decreased in 1991 compared with 1986. But with the price of food crop rising, under driving of economic interest, land clearing began to ride again in survey region. Patches quantity, density and the largest patch index of farmland landscape tended to increase after 1991 to indicate that farmland landscape tended to expand on the whole, especially the southeastern area in 2001.

Compared with 1986, the other years' water landscape tended to decrease except 1991. In a mass, water landscape area decreased $1.97 \%$ in the past 15 years. The decreased water landscape mainly changed to different coverage grassland landscapes. Besides, patches quantity, density and the largest patch index of water landscape were inclined to decrease to indicate natural habitats of grassland vegetation were inclined to deterioration.

Sand landscape area increased $7.74 \%$ annually and the occupied land was mainly higher coverage grassland accounting for $88.60 \%$ of the whole occupied area to indicate that desertification was most serious in the regions with better vegetation condition which was significantly related to human actions. In the 15 years, patches quantity, density of sand landscape increased obviously. Patches quantity and density increased 4 times in 2001 compared with 1986 especially patches quantity in sides of river channel and surrounding of city areas increased obviously. The largest patch 
index decreased to indicate sand landscape fragment degree strengthened. That is because people ignored to protect unsandy grassland vegetation when they supervises serious sandy region.

The grassland vegetation degenerated seriously in 2001. The first 7 months accumulated rainfalls separately are 88.2、185.7、282.9、134mm in 1986、1991、1996、 2001 in survey region and 1996's rainfall is the best. But according to monitoring result of NDVI vegetation index, 1991's vegetation condition is the best and 2001's is the worst and 1986's and 1996's are almost the same. That mainly is because ever since a long time ago, the population and grazing capacity have increased too quickly and grassland utilization intensity continued to increase to make community structure occur to serious retrogressive succession and grassland lose their own ecology self-recovery function. So although the first 7 months' rainfall in 2001 substantially exceeded 1986's, a short term better outside condition can not help vegetation to recovery quickly.

\section{Conclusions and Discussion}

\subsection{Meadow Steppe Self Ecology Recovery Function Is Limited}

Grassland ecology system has definite patent ecology recovery function. Because of better natural conditions, meadow steppe has the strongest recovery function in all types of grasslands. But there are also conditions in exertion of any patent ecology recovery function. Extravagant utilization can make community structure and soil environment occur retrogressive succession and destroy material base where exertion ecology recovery patent function develop the role. Even the recovery function will be lost and grassland makes for continued degeneration. Especially Hulunbuir grassland which has a long collecting grass and barn feeding history, this utilization patterns destroyed completeness of seed resources base and conflicted exertion of self ecology recovery function.

\subsection{Jamming Is the Key Factor in Grassland Vegetation Degeneration}

In the past 15 years, natural factors influencing grassland vegetation had not degenerated dramatically. On the contrary, compared with 1986, accumulated rainfalls of the other three years' first 7 months were far above 1986's meanly. But in the past 15 years, in survey region, population, stock capacity and utilization intensity had increased remarkably; jamming such as land clearing, road repairing, coal digging, oil extraction, crude drugs digging had become quick degeneration accelerator of vegetation condition. All of the jamming led grassland area continued to reduce and vegetation to degenerate especially sand landscape in surroundings of roads, cities and farmlands expanded remarkably. So jamming of human actions was the key factor to lead grassland ecology system deterioration.

\subsection{The Urbanization Level Increased and Economy Development Pattern Changed from Extensive Pattern to Intensive Urbanization Pattern}

In the past 15 years, city landscape area increased remarkably. Fragmentation of city landscape lightened, and city landscape patches tended to decrease and centralized 
than ever especially Hailer region. Although city landscape area increased to occupy a mass of surrounding quality grassland, economy development pattern changed from extensive pattern to intensive pattern to enhance city server function and admit to absorb more surplus manpower in other pasturing area. Especially infrastructure in recreation industry was improved and employment opportunities were increased and economy development pressure faced by grassland landscape was relieved on the whole. It is the only way leading to realizing ecology environment improvement and economy continued development.

\section{Acknowledgements}

This work is supported by Special Fund Project for Basic Science Research Business Fee, Institute of Agricultural Resources and Regional Planning, Chinese Academy of Agricultural Sciences and The National Science \& Technology Program (Grant No. 2006BAC08B0404, 2007BAC03A10) and Project 863 of China: (Grant no. 2007AA 10Z230) and National Natural Science Foundation of China (Grant No: 30770327) and Commonweal Industry Scientific Research Special Funds Project (GYHY 200906029-2).

\section{References}

1. Wu, J.: Landscape Ecology-Pattern, Progress, Scale and level. Advanced Education Press, Beijing (2001)

2. Nagendra, H., Pareeth, S., Ghate, R.: People within parks-forest villages, land - cover change and landscape fragmentation in the Tadoba Andhari Tiger Reserve. India Applied Geography 26(2), 96-112 (2006)

3. Su, Y., Li, Y., Cui, J., et al.: Influences of continuous grazing and livestock exclusion on soil properties in degraded sandy grassland. Inner Mongolia, Northern China, Catena 59(3), 267-278 (2005)

4. Wu, R., Tiessen, H.: Effect of land use on soil degradation in alpine grassland soil, China. Soil Science Society of America Journal 66(5), 1648-1655 (2002)

5. Qing, H., Ranghui, W., Shixin, W.: Spatial temporal dynamic changes of landscape fragmentation in the upper reaches of Tarim river. Journal of Arid Land Resources and Environment 21(9), 73-77 (2007)

6. He, C., Shi, P., Chen, J., et al.: A study on land use/cover change in Beijing area. Geographical Research 20(6), 679-687 (2001)

7. Zhang, Y., Liu, L., Bai, W., et al.: Grassland degradation in the source region of the yellow river. Acta Geographica Sinica 61(1), 3-14 (2006)

8. Wang, H., Yuan, H., Xu, X., et al.: Landscape structure of desertification grassland in source region of yellow river. Chinese Journal of Applied Ecology 17(9), 1665-1670 (2006)

9. Li, J., Liu, G., Li, J.: Research on landscape dynamic change of desert-steppe in Hangjin district Inner Mongolia during last 20years. Chinese Journal of Grassland 29(5), 72-78 (2007)

10. Wamg, M., Bao, Y., Ala, T., Tu, Y., et al.: Analysis on dynamic change of landscape structure of Hunshandake sands. Journal of Arid Land and Resources and Environment 21(5), 121-125 (2007) 
11. Li, Y., Liu, C.: Study on land use/cover change in Xilinhot city. Bulletin of Soil and Water Conservation 26(2), 60-64 (2006)

12. Cao, C., Jiang, D., Zhu, L., et al.: Degradation and diversity changes of meadow grassland in Keerqin sandy land. Acta Prataculturae Sinica 15(3), 18-26 (2006)

13. Tao, W., Xu, B., Yang, X.: Advances and factors affecting the estimating of grass production using remote sensing. Acta Prataculturae Sinica 16(2), 1-8 (2007)

14. Chen, Q.: Grassland deterioration in the source region of the Yangtze-Yellow rivers and integrated control of ecological environment. Acta Prataculturae Sinica 16(1), 10-15 (2007)

15. Chen, Q., Wei, Y., Liang, T.: The investigation of grassland degradation in Dari County of Qinghai province I: remote sensing and mapping. Acta Prataculturae Sinica 7(2), 58-63 (1998)

16. Wang, Q., Luo, P., Wu, N., et al.: Effect of road on high-frigid grassland vegetation of zoige. World Sci.-Tech. R\&D 29(3), 54-61 (2007)

17. Li, J., Zhang, B., Zhang, S.: Dynamic changes in grassland landscape pattern in western Jilin province. Journal of Lanzhou University (Natural Science) 42(4), $43-48$ (2006)

18. Wu, Y., Li, Z.: Changing landscape diversity with time in Xinlinguole steppe. Acta Phytoecologica Sinica 24(1), 58-63 (2000)

19. Liu, X.: Shape index and its ecological significance in salinized meadow landscape. Practaculture Science 17(2), 50-56 (2000)

20. Zhang, T., Xu, D., Wang, H., et al.: Landscape pattern characteristics and landscape ecology construction in medium and down stream of Shule river. Practaculture Science 24(4), 19-22 (2007)

21. Pan, X.: Hulunbuir Grassland in China, pp. 82-96. Jilin Science and Technology Press (1992)

22. Lo, B.: The rangeland degradation in North China and its preventive strategy. Science Agriculture Sinica 30(6), 1-6 (1997)

23. Lu, X., Liu, Q., Li, S., et al.: Chinese Grass Situation, pp. 16-25. KM Press (2002)

24. Liu, D., Lu, X., Zhang, B.: Evaluation of human carrying capacity in the Hulunbeier grassland- a case study in Chenbaerhu Qi in Inner Mongolia, China. Acta Pratacultural Science 16(5), 1-12 (2007)

25. Komatsu, Y., Tsunekawa, A., Ju, H.: Evaluation of agricultural sustainability based on human carrying capacity in dryland -a case study in rural villages in Inner Mongolia, China. Agriculture, Ecosystems and Environment 108, 29-43 (2005)

26. Zhao, H.: The Hulunbei er prairie sand present situation draws back and the preventing and controlling counter measure. Acta Pratacultuae Sinica 16(3), 114-119 (2007)

27. Zhang, D., Wang, X., Hasieerdun, et al.: Hulunbier sandy grassland blowouts: Geomorphology, Classification and Significances. Journal of Desert Research 26(6), 894-901 (2006)

28. Ma, Y., Yu, W., Fang, X.: Change of grass growth in the Hulun Buir steppe in response to global warming. Arid and Geography 27(1), 29-33 (2004)

29. Nie, H., Yue, L., You, M., et al.: Present situation, evolution trend and causes of sandy desertification in Hulunbuir steppe. Journal of Desert Research 25(5), 635-639 (2005)

30. Ren, J.: Study method of practaculture science, pp. 16-52. Chinese Agriculture Press (1998)

31. Tian, Q., Min, X.: Advances in study on vegetation indices. Advance in Earth Sciences 13(4), 327-333 (1998) 